\title{
Evaluation of the Therapeutic Effects of the Hydroethanolic Extract of Portulaca oleracea on Surgical-Induced Peritoneal Adhesion
}

\author{
Ali Jaafari, ${ }^{1,2}$ Vafa Baradaran Rahimi, ${ }^{3}$ Nasser Vahdati-Mashhadian, ${ }^{2}$ \\ Roghayeh Yahyazadeh, ${ }^{2,3}$ Alireza Ebrahimzadeh-Bideskan, ${ }^{4}$ Maede Hasanpour, ${ }^{5}$ \\ Mehrdad Iranshahi, ${ }^{5}$ Sajjad Ehtiati, ${ }^{6}$ Hamed Rajabi, ${ }^{6}$ Mohammadreza Mahdinezhad, ${ }^{6}$ \\ Hassan Rakhshandeh $\mathbb{D D}^{1}$ and Vahid Reza Askari ${ }^{6}{ }^{6,7,8}$ \\ ${ }^{1}$ Pharmacological Research Center of Medicinal Plants, Mashhad University of Medical Sciences, Mashhad, Iran \\ ${ }^{2}$ Departments of Pharmacodynamics and Toxicology, School of Pharmacy, Mashhad University of Medical Sciences, Mashhad, Iran \\ ${ }^{3}$ Department of Cardiovascular Diseases, Faculty of Medicine, Mashhad University of Medical Sciences, Mashhad, Iran \\ ${ }^{4}$ Department of Anatomy and Cell Biology, School of Medicine, Mashhad University of Medical Sciences, Mashhad, Iran \\ ${ }^{5}$ Biotechnology Research Center, Pharmaceutical Technology Institute, Mashhad University of Medical Sciences, Mashhad, Iran \\ ${ }^{6}$ Department of Pharmaceutical Sciences in Persian Medicine, School of Persian and Complementary Medicine, Mashhad University \\ of Medical Sciences, Mashhad, Iran \\ ${ }^{7}$ Applied Biomedical Research Center, Mashhad University of Medical Sciences, Mashhad, Iran \\ ${ }^{8}$ Department of Persian Medicine, School of Persian and Complementary Medicine, Mashhad University of Medical Sciences, \\ Mashhad, Iran
}

Correspondence should be addressed to Hassan Rakhshandeh; rakhshandehh@mums.ac.ir and Vahid Reza Askari; askariv@mums.ac.ir

Received 30 April 2021; Accepted 18 July 2021; Published 2 August 2021

Academic Editor: Matilde Otero-Losada

Copyright (C) 2021 Ali Jaafari et al. This is an open access article distributed under the Creative Commons Attribution License, which permits unrestricted use, distribution, and reproduction in any medium, provided the original work is properly cited.

Objective. Peritoneal adhesion (PA) is an abnormal connective tissue that usually occurs between tissues adjacent to damaged organs during processes such as surgery. In this study, the anti-inflammatory and antioxidant effects of Portulaca oleracea (PO) were investigated against postoperative-induced peritoneal adhesion. Methods. Thirty healthy male Wistar rats (220 $\pm 20 \mathrm{~g}, 6-8$ weeks) were randomly divided into four groups: (1) normal, (2) control (induced peritoneal adhesion), and (3) and (4) PO extracts (induced peritoneal adhesion and received 100 or $300 \mathrm{mg} / \mathrm{kg} /$ day of PO extract for seven days). Finally, macroscopic and microscopic examinations were performed using different scoring systems and immunoassays in the peritoneal lavage fluid. Results. We found that the levels of adhesion scores and interleukin- (IL-) $1 \beta$, IL-6, IL-10, tumour necrosis factor- (TNF-) $\alpha$, transforming growth factor- (TGF-) $\beta_{1}$, vascular endothelial growth factor (VEGF), and malondialdehyde (MDA) were increased in the control group. However, PO extract $(100$ and $300 \mathrm{mg} / \mathrm{kg}$ ) notably reduced inflammatory (IL-1 $\beta$, IL-6, and TNF$\alpha$ ), fibrosis (TGF- $\beta_{1}$ ), angiogenesis (VEGF), and oxidative (MDA) factors, while increased anti-inflammatory cytokine IL-10, antioxidant factor glutathione (GSH), compared to the control group. Conclusion. Oral administration of PO improved postoperational-induced PA by alleviating the oxidative factors, fibrosis, inflammatory cytokines, angiogenesis biomarkers, and stimulating antioxidative factors. Hence, $\mathrm{PO}$ can be considered a potential herbal medicine to manage postoperative PA. However, further clinical studies are required to approve the effectiveness of PO. 


\section{Introduction}

Abnormal connective fibrous tissues join in the surgical area and cause adhesions between the organs and nearby tissues at nonanatomic locations [1]. Notably, infertility, reintervention, abdominal pain, and intestinal occlusion occur following peritoneal adhesions (PA). The progression rate of PA has related to some risk factors such as surgical trauma, genetic factors, presence of infection, and peritoneal contamination during the surgical operation [2]. In particular, peritonitis is considered one of the main reasons for PA progression mentioned in animal and cellular studies. Furthermore, the duration of operation and type of surgical approach directly are related to the PA formation [3]. In this regard, the open procedure (laparotomy) has been more frequently associated with PA than the laparoscopic approach [4]. Also, in the United States in 1998, the economic burden of adhesions was estimated at around 1437.1 million dollars per year [5]. Some studies indicated the reduction of tissue plasminogen activator (tPA)/plasminogen activator inhibitor-1 (PAI-1) ratio [6], increase of transforming growth factor-beta-1 (TGF- $\beta 1$ ), tumour necrosis factoralpha (TNF- $\alpha$ ) [6], interleukin- (IL-) 6 [7], vascular endothelial growth factor (VEGF) [8] and cyclooxygenase (COX), and inhibition of proteolytic enzymes (e.g., matrix metalloproteases (MMPs)) [9], caused to PA development [10]. In addition, further research also proved that upregulation of inducible nitric oxide synthase (iNOS) [9], stress oxidative markers, and myeloperoxidase (MPO) promoted PA progression and development [10]. These alterations are considered underlying factors for the generation of collagen type- 1 and PA development [11]. As primary cells involving PA development, phagocytic and secretory activities of macrophages are increased after five days from surgical procedure and injury by rolling the immune system. Indeed, the surface of the injured area was renewed by macrophages that provide new mesothelial layers with the help of fibroblast cells, usually three to five days after surgical injury [12]. The formation and development of the fibrins were inhibited by chemical agents such as glucocorticosteroids, calcium channel blockers, nonsteroidal anti-inflammatory drugs (NSAIDs), antibiotics, histamine antagonists, and fibrinolytic agents [13]. However, they have no enough effectiveness and efficacy for the prevention or treatment of PA.

The therapeutic advantages of herbal medicine were considered in some research because of its availability, possible efficacy, and safety [14]. Portulaca oleracea L. (PO) is a warm-climate herbaceous, namely, "purslane" in the USA and Australia, a famous rig in Egypt, pigweed in England, pourpier in France, Ma-Chi-Xian in China, and Qurfeh in Iran $[15,16]$. Also, it is the main source of phosphorus, calcium selenium, manganese, iron [17], and omega-3 fatty acids that promote immune function $[16,18]$. There are several reports of benefits of the PO plant, including attenuating effects on cancers, coronary artery disease, hypertension, and inflammatory and autoimmune disorders [16, 19]. Experimentally, it has been shown that the plant has several active constituents, including monoterpenes (portulosides $\mathrm{A}$ and B), diterpenes (portulene), $\beta$-amyrin type triterpenoids, and vitamin A [20]). Besides, it contains $\alpha$-tocopherol, ascorbic acid, B-complex vitamins (niacin, pyridoxine, and riboflavin) [21], and amino acids (leucine, lysine, phenylalanine, methionine, isoleucine, proline, cysteine, valine, threonine, and tyrosine) $[16,22]$. Moreover, further in vivo and in vitro studies represented neuroprotective [18], antidiabetic [23], antioxidant [24], anticancer [25], antiulcerogenic [26], and hepatoprotective [15] effects of PO. However, there is no study evaluating the effectiveness of the oral administration of $\mathrm{PO}$ on preventing surgical-induced peritoneal adhesion. Therefore, in the present study, we investigated the protective effects of PO against the surgical-induced peritoneal adhesion in a rat model.

\section{Materials and Methods}

2.1. Drugs and Chemicals. Ethanol was prepared from SigmaAldrich Chemical Co. (St. Louis, MO, USA). Normal saline was purchased from the Samen ${ }^{\circledR}$ pharmacy factory (Iran). Ketamine and xylazine were obtained from ChemiDaru Company (Iran). Enzyme-linked immunosorbent assay (ELISA) kits, including VEGF, IL- $\beta$, IL-6, TGF- $\beta$, IL-10, and TNF- $\alpha$, were purchased from IBL International ${ }^{\circledR}$ Company (Switzerland), and malondialdehyde (MDA), nitric oxide (NO), and glutathione (GSH) kits were prepared from ZellBio Company (Germany).

2.1.1. Plant Material and Preparation of the Extract. PO (herbarium No. 12-1615-240) was prepared from Mashhad, Khorasan Razavi Province, Iran, in Jan 2020. First, the aerial parts of the plant were freshly prepared then washed and dried in the shadow $\left(25^{\circ} \mathrm{C}\right)$. After the complete drying of the plant, $100 \mathrm{~g}$ of the plant was powdered using a mill. Next, the extract was prepared by the maceration method using $800 \mathrm{ml}$ of $70 \% v / v$ ethanol/water solution for the next $72 \mathrm{~h}$. Afterwards, the obtained liquid extract was concentrated using a rotary evaporator at $40^{\circ} \mathrm{C}$, which yields a solid powder (20\% $w / w$ of dried powder) [27-29]. This powder is stored in the freezer at $-20^{\circ} \mathrm{C}$ until experimenting. Finally, the extract was dissolved in normal saline containing 5\% v/ $v$ Tween 80 [30].

2.1.2. Liquid Chromatography-Mass Spectrometry (LC-MS) Apparatus. The LC-MS analysis was performed using an AB SCIEX QTRAP (Shimadzu) liquid chromatography coupled with a triple quadrupole mass spectrometer. Liquid chromatography separation was performed on a Supelco C18 $(15 \mathrm{~mm} \times 2.1 \mathrm{~mm} \times 3 \mu \mathrm{m})$ column. The analysis was done at a flow rate of $0.2 \mathrm{ml} / \mathrm{min}$. The binary mobile phase consisted of A: $0.1 \%$ formic acid in water and B: $0.1 \%$ formic acid in acetonitrile. The gradient analysis started with $10 \%$ of $\mathrm{B}$, isocratic conditions were maintained for $10 \mathrm{~min}$, gradually turned to $30 \% \mathrm{~B}$ over $20 \mathrm{~min}$, gradually increased to $80 \% \mathrm{~B}$ over $30 \mathrm{~min}$, and held at $80 \% \mathrm{~B}$ for $10 \mathrm{~min}$, and the system was turned to the initial condition of $10 \%$ B in 5 min. Finally, the system was reequilibrated over $5 \mathrm{~min}$. The mass spectra were acquired in a range of 100 to 1700 within the 80 minute scan time. The positive electrospray ionisation (ESI) mode was applied for the mass spectrometer. Mass feature 
TABLE 1: Scoring system for peritoneal adhesion according to the Nair et al. criteria [53].

\begin{tabular}{rr}
\hline Grade & Description of adhesive bands \\
\hline 0 & The complete absence of adhesions \\
1 & Only one band of adhesions among the viscera or between one viscera and the abdominal wall \\
2 & Two bands: among viscera's or from viscera to abdominal wall \\
3 & More than two bands: among viscera or from viscera to the abdominal wall or all intestine making a mass without adhesion to the \\
4 & Viscera adhered directly to the abdominal wall, independent of the number and the extension of adhesion bands
\end{tabular}

extraction of the acquired LC-MS data and maximum detection of peaks was done using the $M Z$ mine analysis software package, version 2.3 .

2.2. Experimental Animals and Ethical Statements. The investigation was performed with male Wistar rats weighing 200$250 \mathrm{~g}$ obtained from the animal laboratory of Faculty of Medicine, Mashhad University of Medical Sciences, Mashhad, Iran. The animals were preserved in the institute animal house at $24 \pm 1^{\circ} \mathrm{C}$ with a $12 / 12 \mathrm{~h}$ light-dark cycle for one week before and through the experiment with free access to water and food. All animal procedures were carried out in compliance with the National Institutes of Health's Guide for the Use and Care of Laboratory Animals guidelines of institutional guidelines. Moreover, the National Institute for Medical Research Development ethical committee approved all procedures involving animals based on the policies of animal experiments and care (Ethical approval code: 971254, Approval date: 2018-07-01, Approval ID: IR.NIMAD.REC.1397.084).

2.3. Model Induction and Grouping and Interventions. To generate abdominal adhesions, the sterilised gauze was used to induce peritoneal abrasion and adhesion. First, all rats were anaesthetised with intraperitoneal (i.p.) injection of $100 \mathrm{mg} / \mathrm{kg}$ ketamine, $10 \mathrm{mg} / \mathrm{kg}$ xylazine, and $3 \mathrm{mg} / \mathrm{kg}$ acepromazine, and then, rats' abdominal hair was carefully shaved and then washed with $70 \% v / v$ ethanol [30]. Next, the sterilised gauze was repeatedly contacted to the peritoneum wall until the appearance of the faded purple spot on the peritoneum. Then, the peritoneal tissue was sutured with nonabsorbable sutures No. 4.0. After that, this area was disinfected with a few drops of chloramphenicol [31-33]. At the end of the surgery, the rats received cefazolin $300 \mathrm{mg} / \mathrm{kg}$ (i.m.) to prevent wound infection $[32,33]$ and then were transferred to the recovery room for grouping and interventions for seven days. The surgery procedure was prolonged to a maximum of ten min. It should be noted that the gavage of groups was performed on the first day after the surgery.

Thirty healthy male Wistar rats $(220 \pm 20$ g, 6-8 weeks) were randomly divided into four groups, as described below: group one, normal (six rats without surgical procedures); group two, control (eight rats induced peritoneal adhesion and gavaged with the vehicle of PO extract for seven consecutive days); group three (low dose, eight rats induced peritoneal adhesion and received $100 \mathrm{mg} / \mathrm{kg} /$ day of PO extract for seven consecutive days); group four (high dose, eight rats induced peritoneal adhesion and received $300 \mathrm{mg} / \mathrm{kg} /$ day of
PO extract for seven consecutive days). The doses of PO were selected according to the preliminary evaluation.

2.4. Assessment of Adhesion Grade. The rats' laparotomy was done on the $8^{\text {th }}$ day after the surgery. The peritoneal adhesion grades were scored via the two scoring systems (Tables 1 and 2) with two independent researchers blinded on the procedure and the grouping.

2.5. Histological Evaluation. In this study, paraffin-embedded histological sections were stained by Masson's trichrome staining to assess the extent and distribution of fibrosis in rats' peritoneal tissue as described by the manufacturer (Sigma-Aldrich) $[34,35]$. In addition, to prepare the peritoneal tissue sample, after removing formalin and washing with distilled water three times, the tissues were transferred to different concentrations of alcohol (50-100\% $v / v)$ for some minutes. Tissue sections were observed with magnifications of 4x, 20x, and 40x using a Nikon E-1000 microscope (Japan) under bright-field optics and photomicrographed using Easy Image 1 (Bergström Instrument $A B$, Sweden).

2.6. Total Protein Measurement Method. The Bradford protein assay was performed to quantify the total protein concentration in a sample [36]. For this reason, first, the Coomassie Brilliant Blue G-250 dye (10 mg) was dissolved in $50 \mathrm{ml}$ ethanol $96 \%$. Then, phosphoric acid $85 \%(10 \mathrm{ml})$ was added and the volume of the solution was increased to $100 \mathrm{ml}$. Next, bovine serum albumin $(4 \mathrm{mg} / \mathrm{ml})$ solution was prepared as a standard curve. Then, after sample pouring $(20 \mu \mathrm{l})$, a Bradford reagent $(200 \mu \mathrm{l})$ was added to the 96well microplate. Finally, the light absorption was read at $595 \mathrm{~nm}$ with a microplate reader after 5 minutes.

2.7. Evaluation of Inflammatory, Angiogenesis, and Fibrosis Biomarkers. According to the manufacturer's instruction, as indices of inflammation, the levels of TNF- $\alpha$, IL- $1 \beta$, and IL6 were measured in peritoneal lavage fluid using ELISA kits $[37,38]$. In addition, the levels of VEGF, as an angiogenesis marker, TGF- $\beta$, as a fibrosis factor, and IL-10, as an antiinflammatory and suppressive cytokine, were also measured in the peritoneal fluid sample by ELISA kits according to the manufacturer's instruction [31, 39].

2.8. Measurement of Oxidant and Antioxidant Parameters. The levels of malondialdehyde (MDA), as an oxidant marker, and glutathione (GSH), as an antioxidant marker, were measured in the peritoneal fluid using commercially available biochemistry kits $[31,38,40]$. 
TABLE 2: Scoring system for peritoneal adhesion according to Adhesion Scoring Scheme [44, 53].

\begin{tabular}{|c|c|}
\hline Grade & Description of adhesive bands \\
\hline 0 & Absence of adhesions \\
\hline 1 & A thin layer adhesion \\
\hline 2 & More than a thin layer adhesion \\
\hline 3 & Thick adhesive tissue attached to the surgical site \\
\hline 4 & Thick adhesive tissue attached to different areas of the abdomen \\
\hline 5 & Thick adhesive tissue containing blood vessels or too much adhesive tissue or organ adhesive tissue \\
\hline
\end{tabular}

TABle 3: Peak assignment of metabolites in the hydroethanol extract of PO using LC-MS in the positive mode.

\begin{tabular}{|c|c|c|c|c|}
\hline Peak No. & Compound identification & $t_{\mathrm{R}}(\min )$ & $\mathrm{M}+\mathrm{H}(m / z)$ & Ref. \\
\hline 1 & Portulacanone D & 26.9 & 299.76 & {$[25]$} \\
\hline 2 & Noradrenaline & 37.0 & 170.7 & {$[54]$} \\
\hline 3 & Dopa & 15.0 & 198.12 & {$[55]$} \\
\hline 4 & Oleraceins A & 62.5 & 504.66 & {$[55]$} \\
\hline 5 & Oleraceins B & 9.5 & 533.76 & {$[55]$} \\
\hline 6 & Oleraceins C & 64.1 & 666.06 & {$[55]$} \\
\hline 7 & Oleraceins D & 13.1 & 696.84 & {$[55]$} \\
\hline 8 & Adenosine & 19.8 & 268.8 & {$[55]$} \\
\hline 9 & (3R)-3,5-Bis(3-methoxy-4-hydroxyphenyl)-2,3-dihydro-2(1H)-pyridinone & 89.3 & 342.36 & {$[56]$} \\
\hline 10 & Aurantiamide acetate & 36.4 & 445.8 & {$[57]$} \\
\hline 11 & Cyclo(L-tyrosinyl-L-tyrosinyl) & 67.7 & 327.24 & [57] \\
\hline 12 & Portuloside A & 72.2 & 332.22 & {$[58]$} \\
\hline 13 & Portulene & 66.3 & 337.02 & [15] \\
\hline 14 & Lupeol & 66.5 & 427.5 & [15] \\
\hline 15 & (3S)-3-O-( $\beta$-D-Glucopyranosyl)-3,7-dimethylocta-1,6-dien-3-ol & 67.8 & 318.12 & [59] \\
\hline 16 & Friedelane & 54.9 & 413.34 & [60] \\
\hline 17 & Quercetin & 39.4 & 303.18 & [61] \\
\hline 18 & Myricetin & 55.1 & 318.24 & [61] \\
\hline 19 & Genistin & 65.4 & 433.20 & [62] \\
\hline 20 & Indole-3-carboxylic acid & 77.8 & 162.90 & {$[25]$} \\
\hline 21 & Palmitic acid & 62.2 & 256.14 & {$[63]$} \\
\hline 22 & Stearic acid & 37.8 & 285.18 & {$[63]$} \\
\hline 23 & Caffeic acid & 65.8 & 181.08 & {$[64]$} \\
\hline 24 & Riboflavin & 35.0 & 376.62 & {$[21]$} \\
\hline 25 & Vitamin C & 28.5 & 177.00 & {$[21]$} \\
\hline 26 & $\alpha$-Tocopherol & 67.1 & 431.22 & {$[63]$} \\
\hline 27 & Hesperidin & 76.8 & 611.58 & {$[65]$} \\
\hline 28 & Portulacerebroside A & 64.6 & 843.18 & {$[60]$} \\
\hline 29 & $\beta$-Sitosterol & 48.7 & 415.32 & [15] \\
\hline 30 & $\beta$-Carotene & 37.5 & 538.74 & {$[63]$} \\
\hline
\end{tabular}

2.9. Statistical Analysis. Data were analysed using GraphPad Prism software (version 6.01) and represented as mean \pm $\mathrm{SD}$ and median \pm interquartile range (IQR), according to the nature of parametric or nonparametric data, respectively. A one-way analysis of variance (ANOVA) was performed with Tukey's Kramer multiple comparison posttest for parametric data. However, for the nonparametric data (adhesion scores), a Kruskal-Wallis' test was performed with Dunn's multiple comparison post hoc test. $P$ values $(P)$ when lower than 0.05 were considered statistically significant $[28,39,40]$.

\section{Results}

3.1. LC-MS Analysis of PO Extract. In total, 30 compounds were identified in the hydroethanolic extract of the aerial parts of PO, mainly including alkaloids, flavonoids, 




(a)

Figure 1: Continued. 


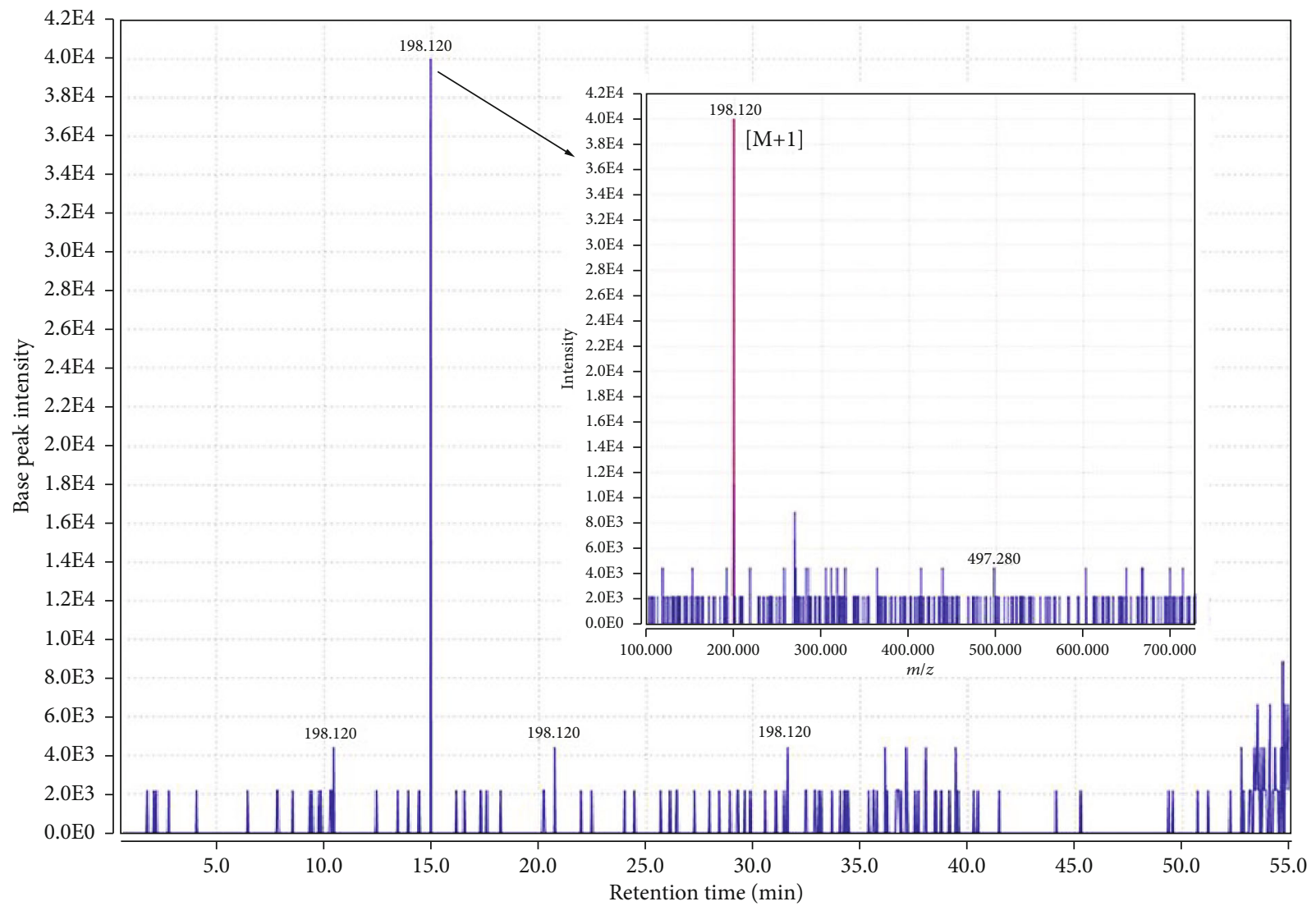

(b)

Figure 1: Continued. 


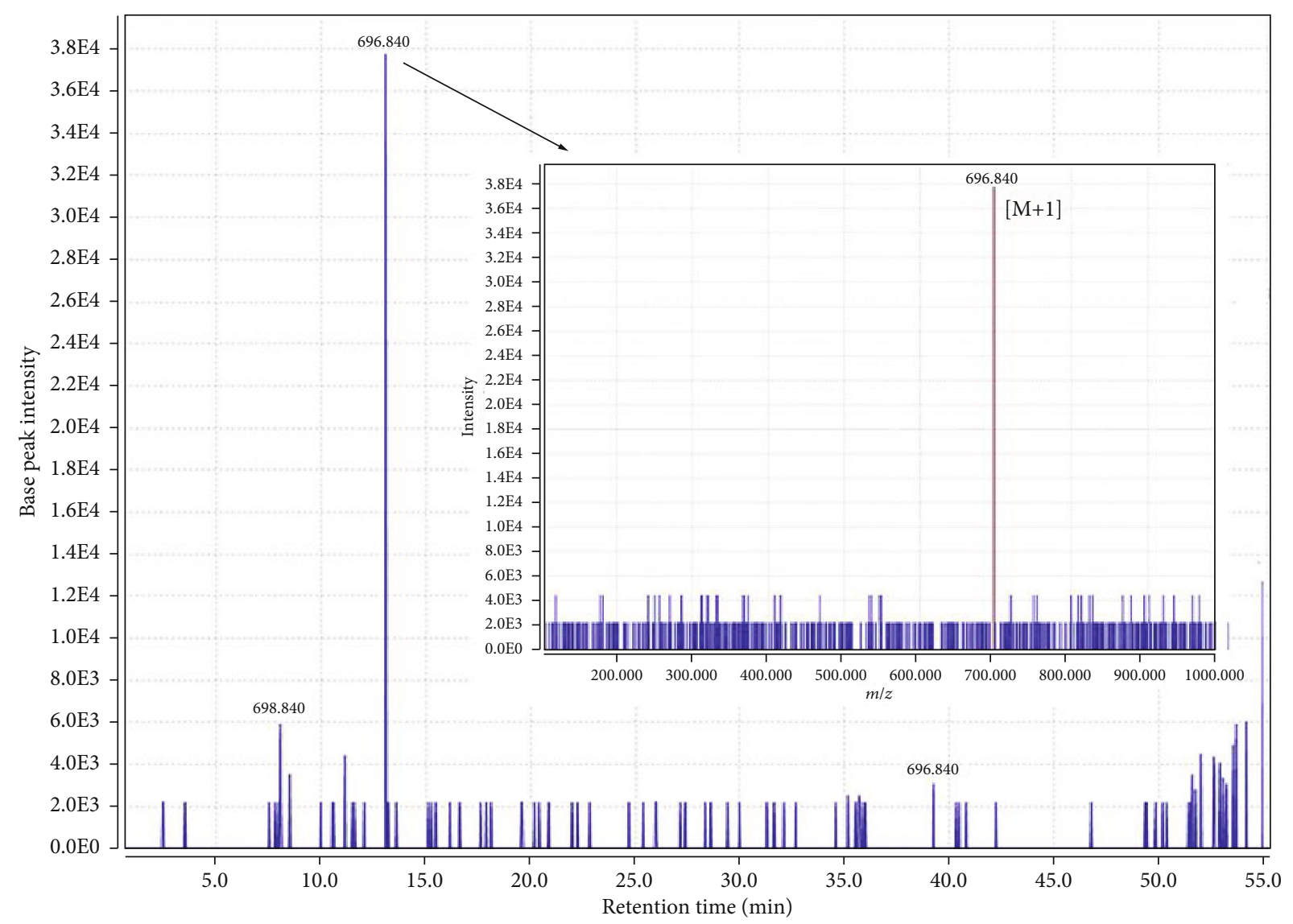

(c)

Figure 1: Continued. 


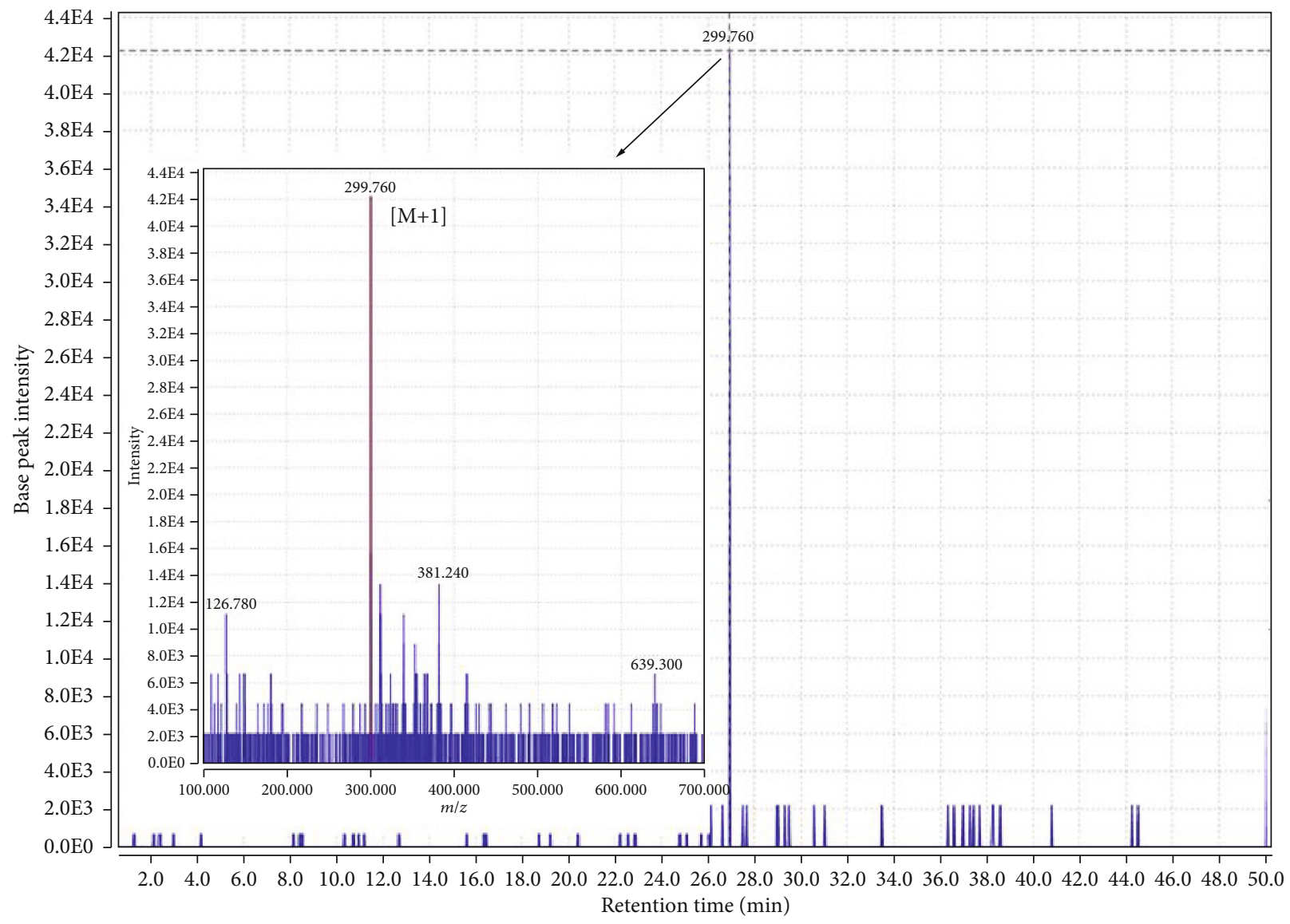

(d)

Figure 1: Continued. 


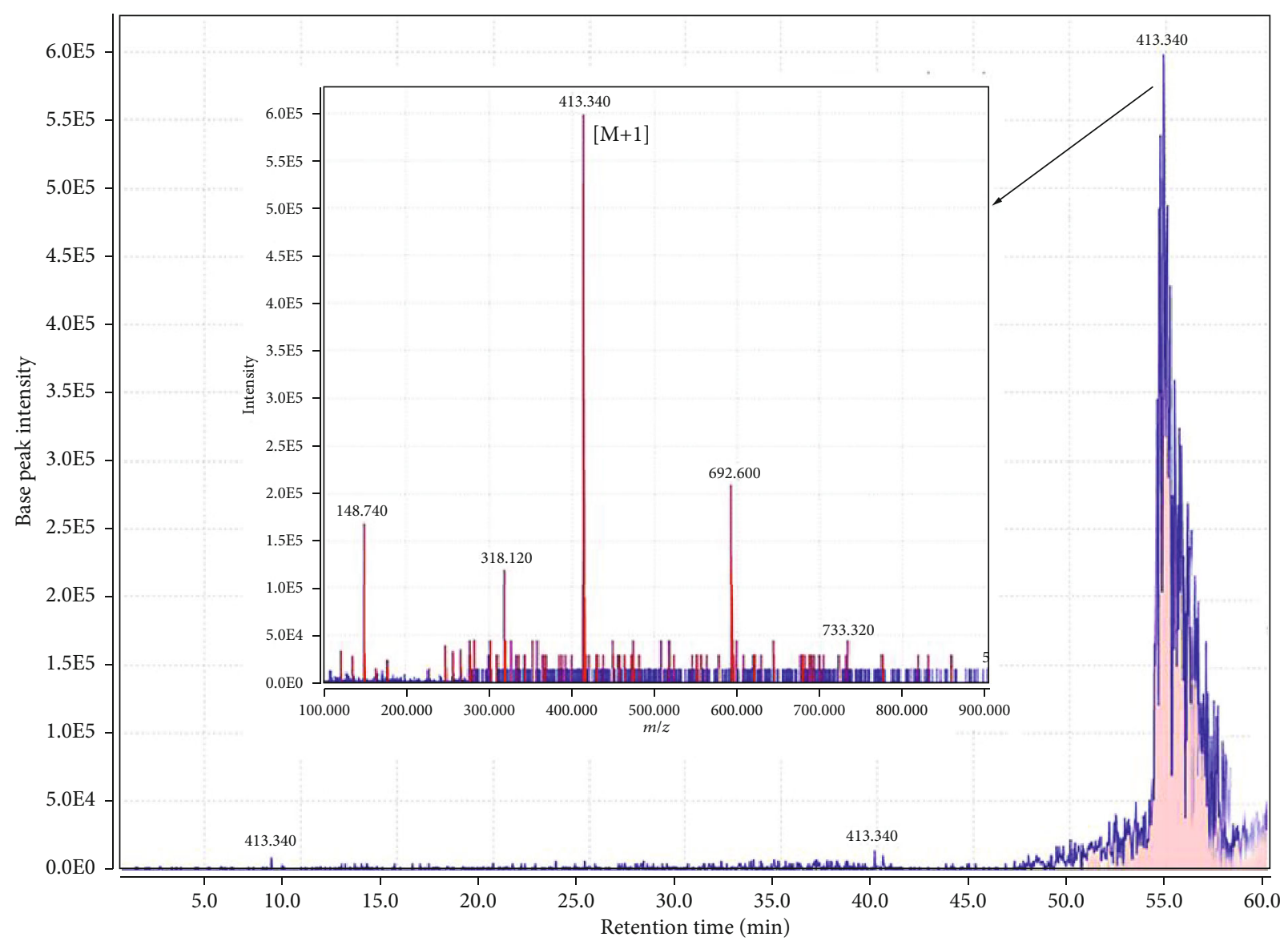

(e)

Figure 1: Continued. 


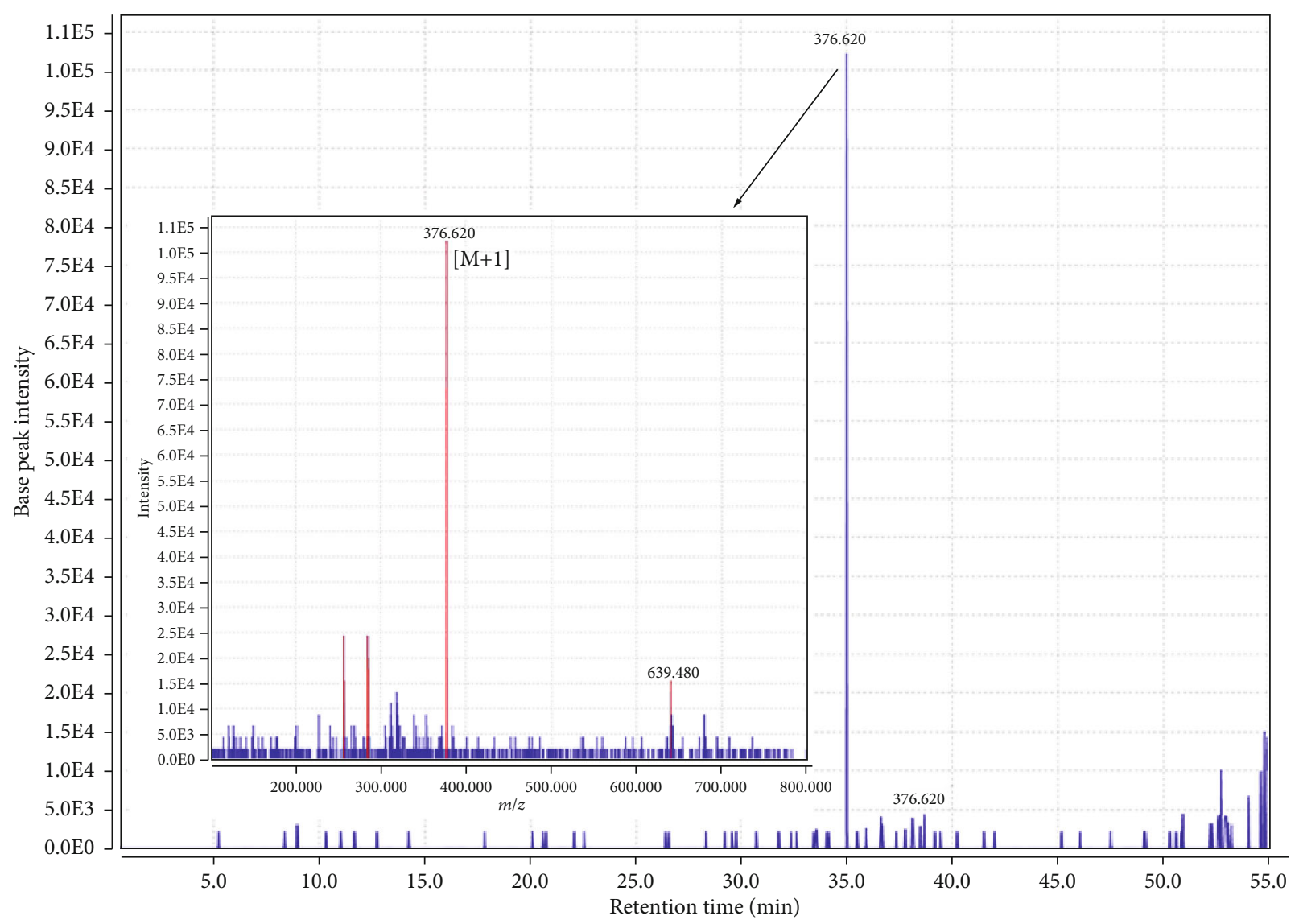

(f)

Figure 1: Continued. 


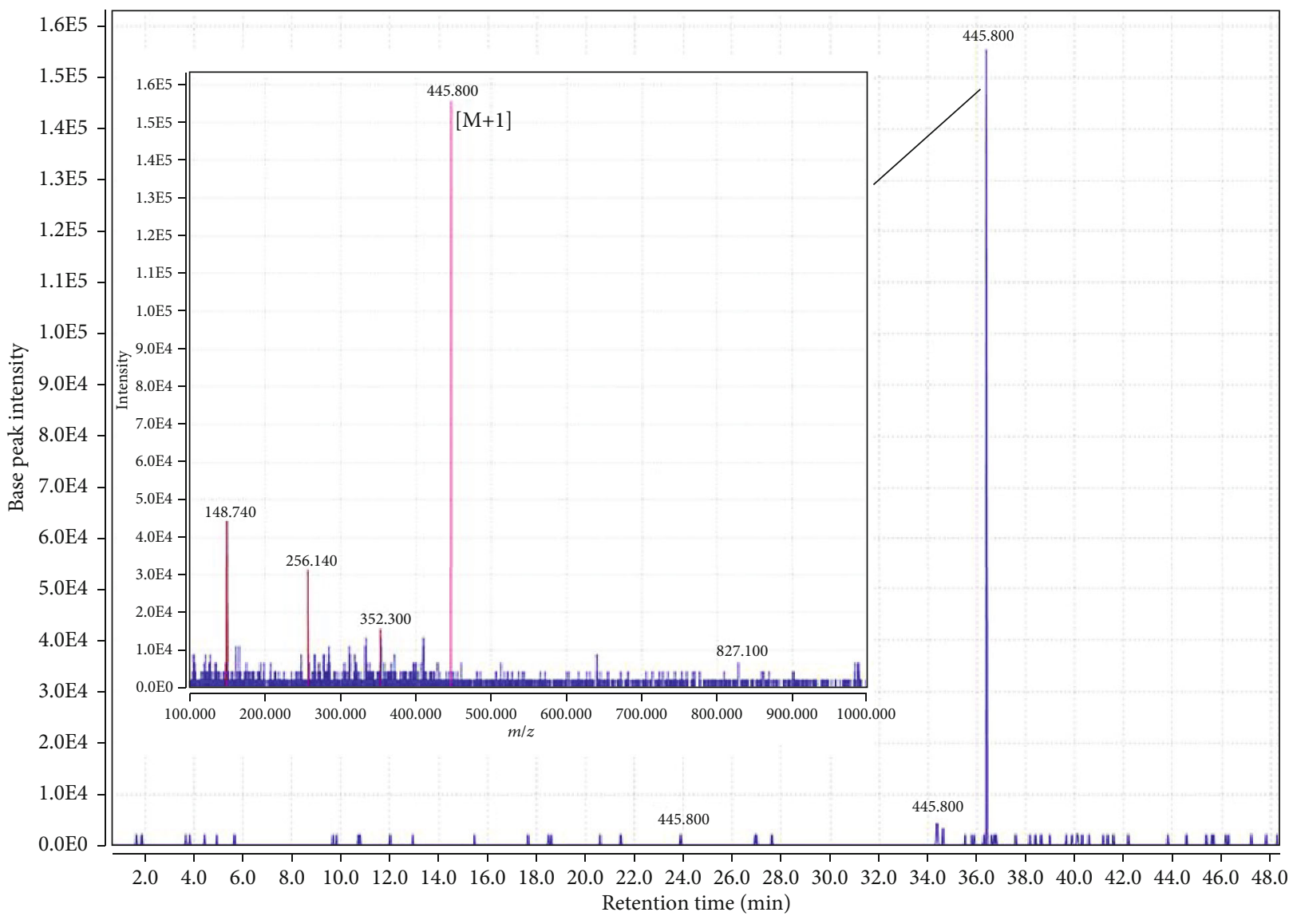

(g)

Figure 1: (a) The total ion chromatogram of Portulaca oleracea extract; (b) chromatogram of dopa and corresponding mass adduct, [M +1 , at $\mathrm{m} / \mathrm{z}$ 198.120; (c) chromatogram of oleraceins $\mathrm{D}$ and corresponding mass adduct, $[\mathrm{M}+1]$, at $\mathrm{m} / \mathrm{z} 696.84$; (d) chromatogram of portulacanone $\mathrm{D}$ and corresponding mass adduct, $[\mathrm{M}+1]$, at $\mathrm{m} / z$ 299.76; (e) chromatogram of friedelane and corresponding mass adduct, $[\mathrm{M}+1]$, at $\mathrm{m} / \mathrm{z} 413.34$; (f) chromatogram of riboflavin and corresponding mass adduct, [M+1], at $\mathrm{m} / \mathrm{z} 376.62$; (g) chromatogram of aurantiamide acetate and corresponding mass adduct, $[\mathrm{M}+1]$, at $\mathrm{m} / z 445.8$.

terpenoids, and vitamins. Data concerning the identification of the compounds are represented in Table 3. The total ion chromatogram of PO extract is shown in Figure 1(a). In addition, the MS spectral data were compared with the reported compounds in some previous literature. Examples of extracted ion chromatograms from the total ion chromatogram and its related mass are represented in Figures 1(b)-1(g). Alkaloids are one of the important chemicals found in PO, including dopa, noradrenalin, and oleraceins $\mathrm{A}, \mathrm{B}, \mathrm{C}$, and D (cyclodopa alkaloids). Moreover, PO contains monoterpenes (portulosides A), diterpenes (portulene), ascorbic acid, $\alpha$ tocopherol, and riboflavin.

3.2. The Effects of PO Extract on Peritoneal Adhesion (PA) Scoring. A macroscopic evaluation of PA scores was performed at the end of the experiment (Figure 2). We found that the PA scores were significantly increased in the control group compared to the standard group $(P<0.01$ for both scoring systems, Figures 3(a) and 3(b)). Conversely, both doses of PO (100 and $300 \mathrm{mg} / \mathrm{kg})$ markedly abolished the

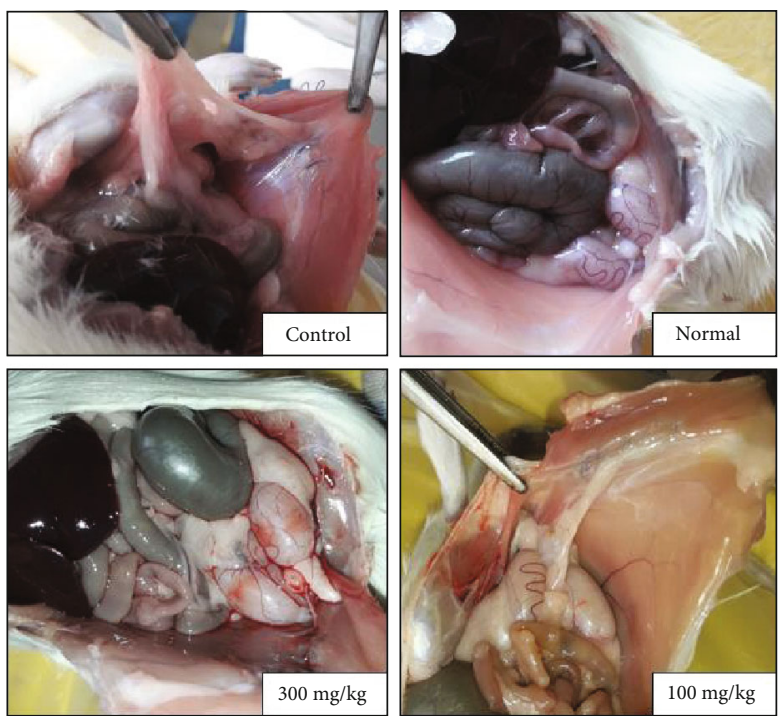

FIgURE 2: Macroscopic evaluation of PA bands in normal, control, and $\mathrm{PO}$ at doses of 100 and $300 \mathrm{mg} / \mathrm{kg}$ groups. 


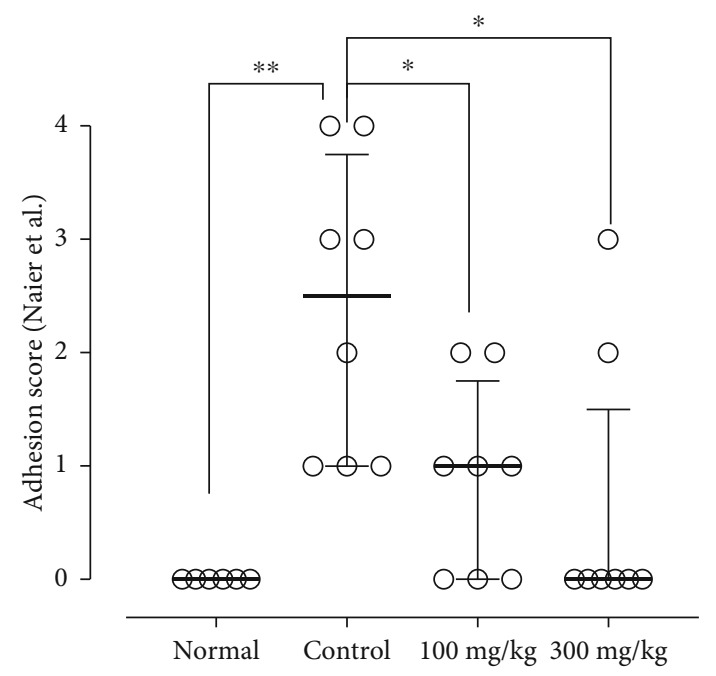

(a)

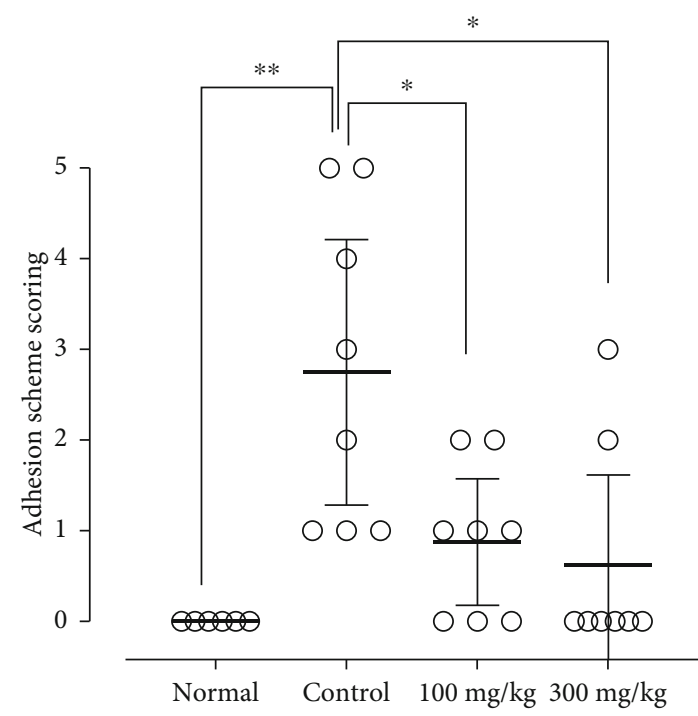

(b)

FIgURE 3: The effects of different doses of PO on adhesion scores evaluated by Naier et al. (a) and Adhesion Scoring Scheme (b) scoring systems; data were presented as median \pm interquartile range, IQR $(n=8$ for all groups except normal as 6$)$. ${ }^{*} P<0.05$ and ${ }^{* *} P<0.01$.
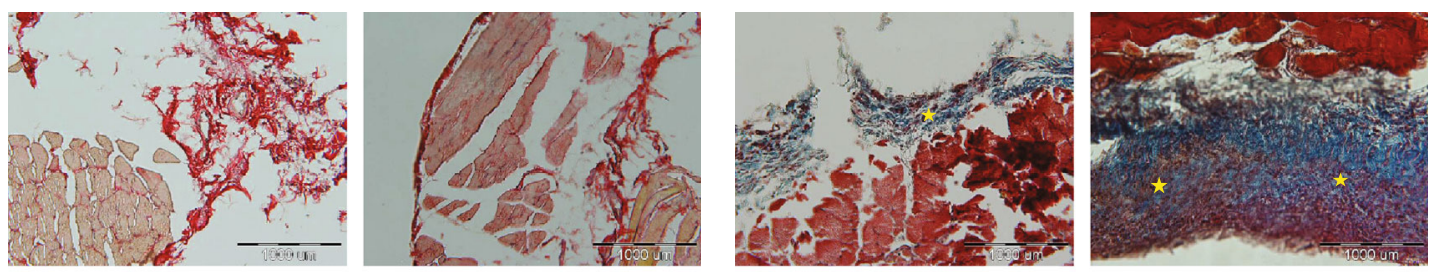


(a)
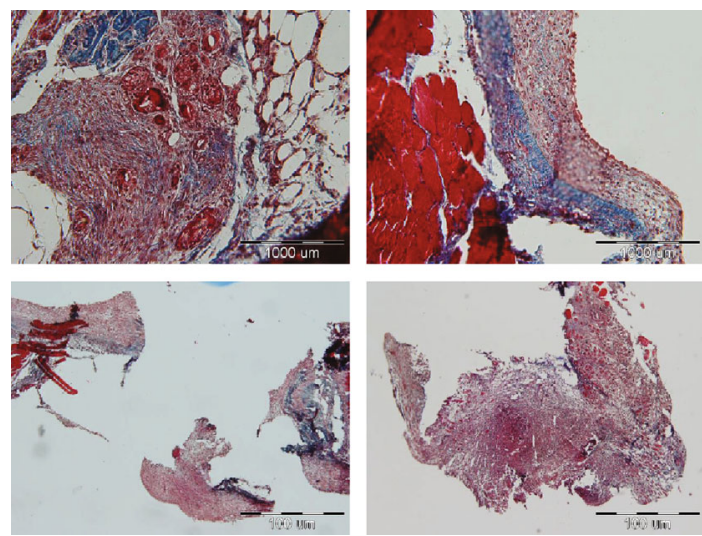

(c)
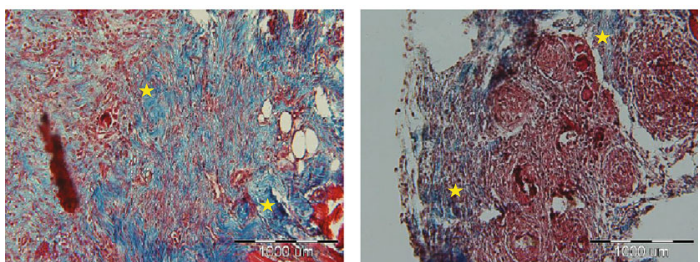

(b)
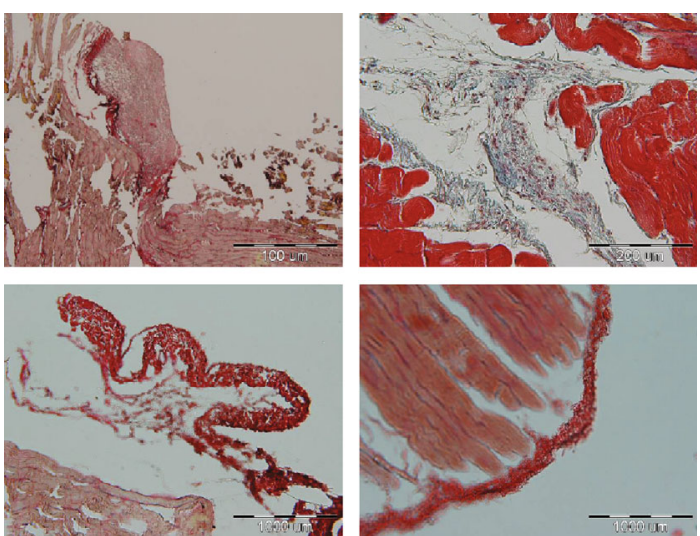

(d)

FIgURE 4: The effects of different doses of PO on adhesion formation and collagen deposition by histopathological evaluation using Masson's trichrome staining; blue colour intensities (marked with yellow stars) represent fibrosis and collagen deposition. Pathological imaging; (a) normal group, (b) control group, (c) PO at the dose of $100 \mathrm{mg} / \mathrm{kg}$, and (d) PO at the dose of $300 \mathrm{mg} / \mathrm{kg}$. The highest rate of tissue fibrosis (blue colour) and collagen deposition was observed in the control group (b) compared to the normal group (a), which had the lowest fibrosis rate. Conversely, the blue colour intensities as a marker of fibrosis and collagen deposition in both doses of the extract groups (100 and $300 \mathrm{mg} / \mathrm{kg}$ ) were significantly decreased compared to the control group (c, d). 


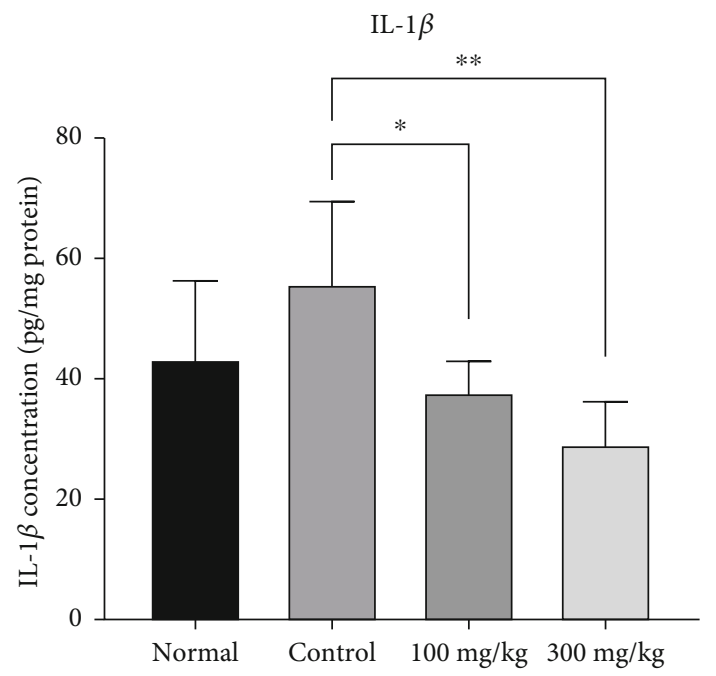

(a)

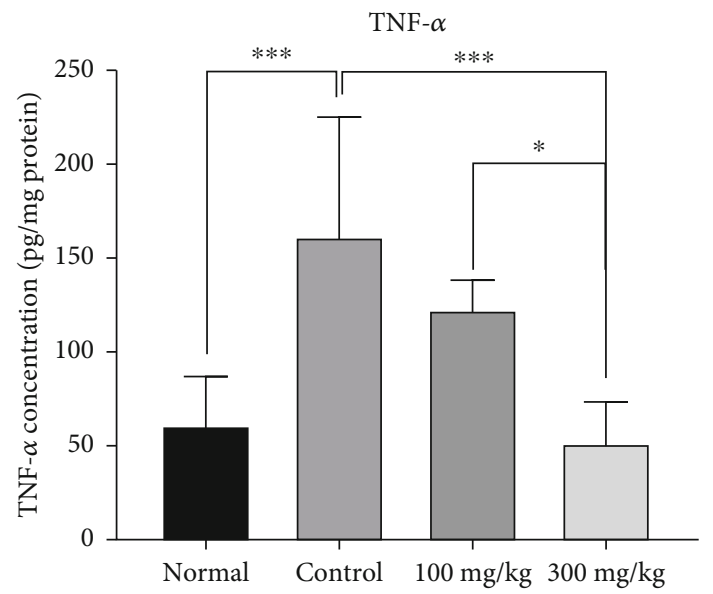

(c)

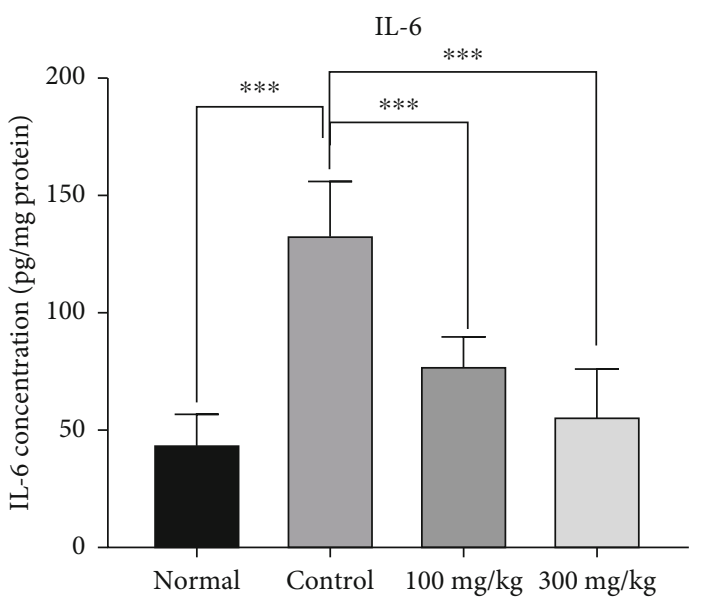

(b)

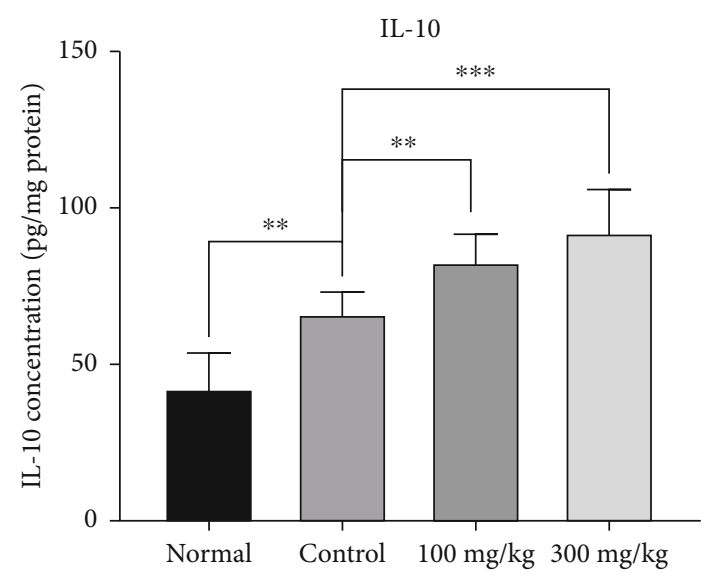

(d)

Figure 5: The effects of different doses of PO on the peritoneal lavage levels of (a) IL-1 $\beta$, (b) IL-6, (c) TNF- $\alpha$, and (d) IL-10; data were presented as mean $\pm \operatorname{SD}(n=8$ for all groups except normal as 6$)$. ${ }^{*} P<0.05,{ }^{* *} P<0.01$, and ${ }^{* * *} P<0.001$.

PA scores compared to the control group $(P<0.05$ for both cases and scoring systems).

3.3. The Effects of PO Extract on Histopathological Alteration of Peritoneal Fibrosis. The histopathological study was performed using Masson's trichrome staining to evaluate the rate of peritoneal fibrosis. As shown in Figure 4, the highest rate of tissue fibrosis (blue colour) and collagen deposition was observed in the control group (Figure 4(b)) compared to the normal group (Figure 4(a)), which had the lowest fibrosis rate. In contrast, the blue colour intensities as a marker of fibrosis and collagen deposition in both doses of the extract groups (100 and $300 \mathrm{mg} / \mathrm{kg}$ ) were significantly decreased compared to the control group (Figures 4(c) and 4(d)).

3.4. The Effects of PO Extract on Inflammatory and AntiInflammatory Biomarkers. Our results indicated that the levels of inflammatory mediators, including IL-6 $(P<0.001$, Figure 5(b)) and TNF- $\alpha(P<0.001$, Figure 5(c)), and antiinflammatory cytokine IL-10 $(P<0.01$, Figure $5(d))$ were significantly increased in the control group compared to the normal group. However, the level of IL- $1 \beta$ was greater than the normal group, but this increment was not statistically significant (Figure 5(a)). Administration of PO for seven consecutive days notably reduced the levels of IL- $1 \beta$ $(100 \mathrm{mg} / \mathrm{kg}, \quad P<0.05, \quad$ and $\quad 300 \mathrm{mg} / \mathrm{kg}, \quad P<0.001$, Figure 5(a)), IL-6 $(P<0.001$ for 100 and $300 \mathrm{mg} / \mathrm{kg}$, Figure 5(b)), and TNF- $\alpha(300 \mathrm{mg} / \mathrm{kg}, P<0.001$, Figure 5(c)) and significantly elevated the level of IL-10 (100 mg/kg, $P<$ 0.01 , and $300 \mathrm{mg} / \mathrm{kg}, P<0.001$, Figure $5(\mathrm{~d}))$ in the peritoneal lavage fluid, compared to the control group.

3.5. The Effects of PO Extract on Fibrosis and Angiogenesis Parameters. Following the PA, the levels of TGF- $\beta 1$ as a fibrotic factor and VEGF as an angiogenesis factor were significantly enhanced in the control group compared to the normal group $(P<0.001$ for both cases, Figures $6(\mathrm{a})$ and $6(\mathrm{~b})$ ). In contrast, the use of $300 \mathrm{mg} / \mathrm{kg} /$ day PO significantly mitigated the levels of TGF- $\beta 1$ and VEGF compared to the control group $(P<0.001$ for both cases, Figures 6(a) and $6(\mathrm{~b}))$. However, $100 \mathrm{mg} / \mathrm{kg} /$ day of $\mathrm{PO}$ could significantly attenuate the level of TGF- $\beta 1$ compared to the control group 


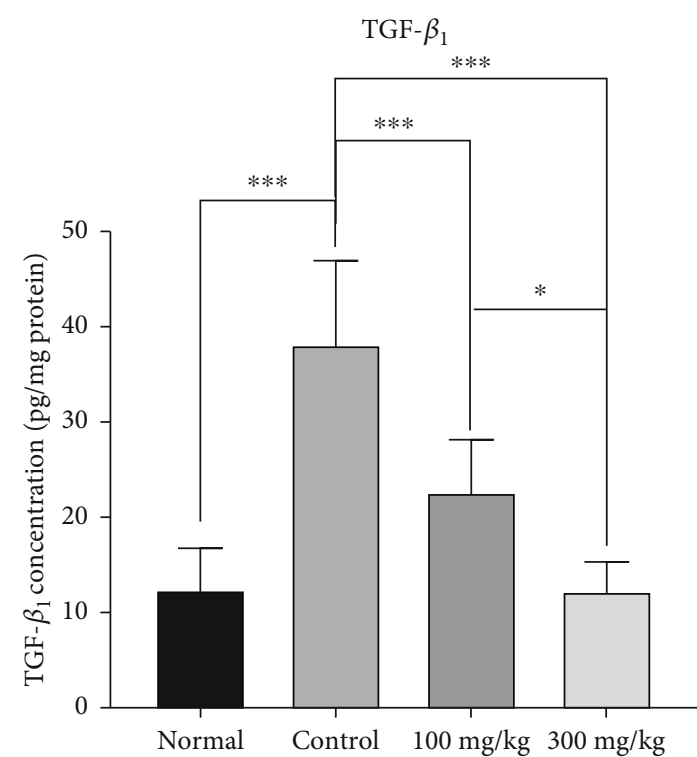

(a)

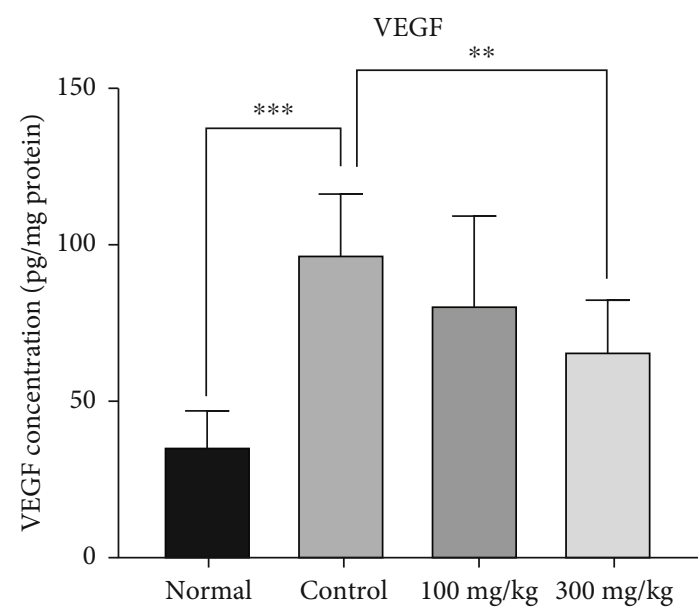

(b)

Figure 6: The effects of different doses of PO on the peritoneal lavage levels of (a) TGF- $\beta$ and (b) VEGF; data were presented as mean \pm SD ( $n=8$ for all groups except normal as 6 ). ${ }^{*} P<0.05,{ }^{* *} P<0.01$, and ${ }^{* * *} P<0.001$.

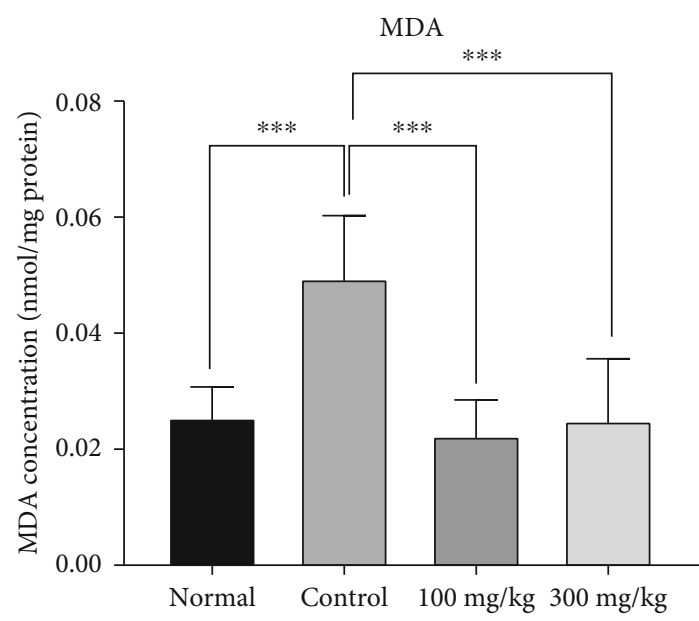

(a)

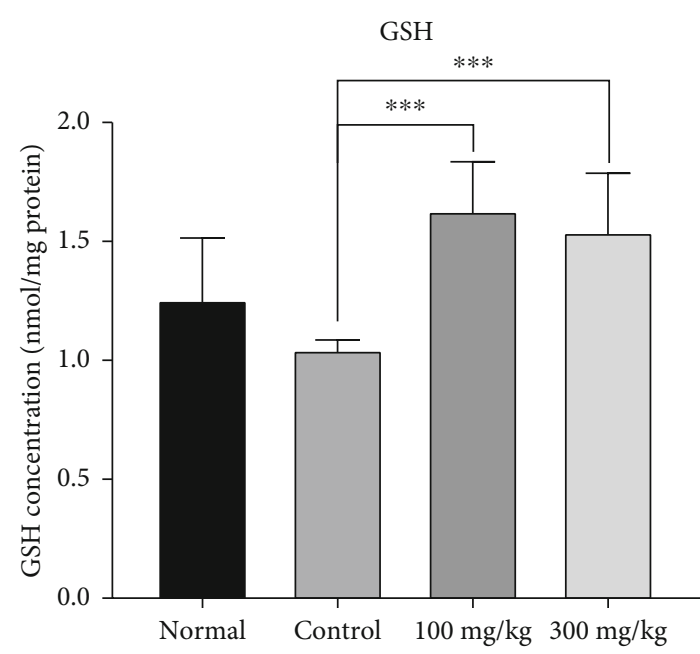

(b)

FIGURE 7: The effects of different doses of PO on the peritoneal lavage levels of (a) MDA and (b) GSH; data were presented as mean \pm SD $(n=8$ for all groups except normal as 6$) .{ }^{* *} P<0.01$ and ${ }^{* * *} P<0.001$.

$(P<0.001$, Figure 6(a)). Moreover, the results indicated that the suppressive effect of $300 \mathrm{mg} / \mathrm{kg} /$ day PO on TGF- $\beta 1$ level was more than $100 \mathrm{mg} / \mathrm{kg} /$ day PO $(P<0.05$, Figure 6(a)).

\subsection{The Effects of PO Extract on Oxidant and Antioxidant} Levels. The results revealed that the MDA level was significantly elevated in the control group compared to the normal group $(P<0.001$, Figure $7(\mathrm{a}))$. Nevertheless, 100 and $300 \mathrm{mg} / \mathrm{kg} /$ day $\mathrm{PO}$ administration remarkably abolished the MDA levels compared to the normal group $(P<0.001$ for both cases, Figure 7(a)). Following the PA induction, we observed that the level of GSH slightly decreased in the control group in comparison to the normal group (Figure $7(\mathrm{~b})$ ).
However, administration of PO (100 and $300 \mathrm{mg} / \mathrm{kg} /$ day) considerably augmented the GSH levels in peritoneal lavage fluid compared to the control group $(P<0.001$ for both cases, Figure 7(b)).

\section{Discussion}

To the best of our knowledge, this is the first study evaluating the effects of oral administration of PO extract on PA in a rat model. As a result, we found that PO at both doses significantly reduced the adhesion formation score by lowering the inflammatory cytokines (IL- $\beta$, IL-6, and TNF- $\alpha$ ), increasing the anti-inflammatory cytokine IL-10, and 
suppressing TGF- $\beta 1$ and VEGF as fibrotic and angiogenesis factors, respectively. Moreover, PO extract regulated the imbalanced oxidant/antioxidant markers by lowering MDA level as a marker of lipid peroxidation and enhancing GSH level as an antioxidant system's reservoir.

The peritoneum is a thin and delicate membrane covering the abdominal cavity and protects and structures internal organs. Some pathologic processes, including ischemia, haemorrhage, endometriosis, infections, trauma, and surgical procedures, cause PA generation in the overwhelming majority of patients $[12,41]$. Nevertheless, its effects in everlasting fibrinous adhesions are influenced by the integrity of the fibrinolytic system [42]. Several investigations showed that inflammatory cytokines, including TNF- $\alpha$, IL- 6 , and IL- $1 \beta$, are the primary reasons for PA generation $[30,43,44]$. In this regard, our investigation also revealed that the levels of the inflammatory cytokines (TNF- $\alpha$, IL-6, and IL- $1 \beta$ ) were meaningfully increased in the control group following postoperational-induced PA. In contrast, PO at both doses markedly abolished these inflammatory markers. In line with our findings, it has been reported that administration of PO (200 and $400 \mathrm{mg} / \mathrm{kg} /$ day for four weeks) significantly abrogated systemic oxidative stress (MDA) and inflammatory markers (TNF- $\alpha$ and IL-6) in streptozotocin-induced diabetic rats [45].

Transforming growth factor- $\beta$ (TGF- $\beta$ ), as a pleiotropic cytokine, modulates the immune system activity of $\mathrm{T}$ cells and regulates inflammation [30,46]. VEGF is the essential angiogenesis activator. It also induced leakage and proliferating in endothelial cells to the adhesion site and generated new blood vessels [47, 48]. The Cahill et al. investigation results revealed that suppressing the VEGF via VEGF monoclonal antibody (bevacizumab) mitigates PA formation in mice [49]. In fact, both VEGF and TGF- $\beta 1$ expression levels are increased during the PA process $[47,48,50]$. Our present study demonstrated that VEGF and TGF- $\beta 1$ levels were significantly elevated in the control group following the postoperational-induced PA compared to the normal group accordingly. In immunohistological research, treatment of mice with PO (300 mg/kg/day, p.o., for ten weeks) revealed that it could reduce the expression levels of advanced glycation end products (AGE), TGF- $\beta 1$, and intercellular adhesion molecule- (ICAM-) 1 in diabetic nephropathy through suppression of renal fibrosis and inflammation in diabetic $d b / d b$ mice [50]. Similarly, PO extract $(300 \mathrm{mg} / \mathrm{kg} /$ day, p.o., for ten weeks) reduced vascular-related adhesion molecules such as endothelial vascular cell adhesion molecule-1 (VCAM-1), intercellular adhesion molecule-1 (ICAM-1), and E-selectin in diabetic $d b / d b$ mice [51]. Moreover, we also exhibited that the PO extract (100 and $200 \mathrm{mg} / \mathrm{kg}$, p.o.) inhibited lung inflammation by downregulating TNF- $\alpha$, IL6 , IL- $\beta$, TGF- $\beta$, and $\mathrm{PGE}_{2}$ levels and upregulating the expression level of IL-10 [29]. In addition, it was found that PO abolished the lung wet/dry ratio that was an index of oedema and improved the levels of MDA, MPO, WBC, thiol group formation, and CAT and SOD activities compared with the LPS group [29].

One of the essential parameters of PA generation is oxidative stress [52]. Hence, in the current study, we investi- gated the levels of MDA and GSH as oxidant/antioxidant markers. Our data emphasised that PO meaningfully reduced the level of MDA and enhanced the GSH level following the postoperational-induced PA. Furthermore, it has been reported that the $\mathrm{PO}$ extract could elevate the SOD and CAT levels, while downregulating the MDA level in lipopolysaccharide- (LPS-) induced acute lung injury rats [37]. In this context, another study indicated that the PO extract improves SOD and GSH levels and prevents MDA and IL-6 levels in the STZ-induced diabetic rats [45]. Thus, these studies can support our findings on the antioxidant activity of PO that led to the reduction of adhesion formation.

In conclusion, our investigation represented that oral administration of PO improved postoperational-induced PA via alleviating the oxidative factors, fibrosis, inflammatory cytokines, angiogenesis biomarkers, and stimulating antioxidative factors. Hence, $\mathrm{PO}$ can be considered a potential herbal medicine to manage postoperative PA. However, further clinical studies are required to approve the effectiveness of PO.

\section{Data Availability}

The data used to support the findings of this study are available from the corresponding author upon reasonable request.

\section{Ethical Approval}

All procedures involving animals were approved by the ethical committee based on the guidelines of animal experiments in the National Institute for Medical Research Development (Ethical approval code: 971254, Approval date: 2018-0701, Approval ID: IR.NIMAD.REC.1397.084).

\section{Consent}

All persons gave their informed consent before their inclusion in the study.

\section{Conflicts of Interest}

The authors declare that there is no conflict of interest.

\section{Authors' Contributions}

Ali Jaafari and Vafa Baradaran Rahimi shared the first coauthorship.

\section{Acknowledgments}

Research reported in this publication was supported by the Elite Researcher Grant Committee under award number 971254 from the National Institute for Medical Research Development (NIMAD), Tehran, Iran.

\section{References}

[1] K. M. Braun and M. P. Diamond, "The biology of adhesion formation in the peritoneal cavity," Seminars in Pediatric Surgery, vol. 23, no. 6, pp. 336-343, 2014. 
[2] H. Toh, M. Torisu, H. Shimura et al., "In Vitro Analysis of Peritoneal Adhesions in Peritonitis," The Journal of Surgical Research, vol. 61, no. 1, pp. 250-255, 1996.

[3] A. Moreno, J. L. Aguayo, G. Zambudio, P. Ramirez, M. Canteras, and P. Parrilla, "Influence of abdominal incision on the formation of postoperative peritoneal adhesions: an experimental study in rats," The European Journal of Surgery, vol. 162, no. 3, pp. 181-185, 1996.

[4] A. Tittel, E. Schippers, K. H. Treutner et al., "Laparoscopy versus laparotomy. An animal experiment study comparing adhesion formation in the dog," Langenbecks Archiv fur Chirurgie, vol. 379, no. 2, pp. 95-98, 1994.

[5] N. F. Ray, W. G. Denton, M. Thamer, S. C. Henderson, and S. Perry, "Abdominal adhesiolysis: inpatient care and expenditures in the United States in 1994," Journal of the American College of Surgeons, vol. 186, no. 1, pp. 1-9, 1998.

[6] M.-L. Ivarsson, M. P. Diamond, P. Falk, and L. Holmdahl, "Plasminogen activator/plasminogen activator inhibitor-1 and cytokine modulation by the PROACT ${ }^{\mathrm{TM}}$ system," Fertility and Sterility, vol. 79, no. 4, pp. 987-992, 2003.

[7] D. R. Ambler, N. M. Fletcher, M. P. Diamond, and G. M. Saed, "Effects of hypoxia on the expression of inflammatory markers IL-6 and TNF-a in human normal peritoneal and adhesion fibroblasts," Systems Biology in Reproductive Medicine, vol. 58, no. 6, pp. 324-329, 2012.

[8] V. I. Shavell, G. M. Saed, and M. P. Diamond, "Review: cellular metabolism: contribution to postoperative adhesion development," Reproductive Sciences, vol. 16, no. 7, pp. 627-634, 2009.

[9] Z. Alpay, G. M. Saed, and M. P. Diamond, "Female infertility and free radicals: potential role in adhesions and Endometriosis," The Journal of the Society for Gynecologic Investigation: JSGI, vol. 13, no. 6, pp. 390-398, 2006.

[10] G. M. Saed, A. AL-Hendy, S. A. Salama, and M. P. Diamond, "Adenovirus-mediated expression of cyclooxygenase- 2 antisense reverse abnormal genetic profile of human adhesion fibroblasts," Fertility and Sterility, vol. 89, no. 5, pp. 14551460, 2008.

[11] N. M. Fletcher, Z. L. Jiang, M. P. Diamond, H. M. Abu-Soud, and G. M. Saed, "Hypoxia-generated superoxide induces the development of the adhesion phenotype," Free Radical Biology and Medicine, vol. 45, no. 4, pp. 530-536, 2008.

[12] G. Saed and M. Diamond, "Molecular characterization of postoperative adhesions: the adhesion phenotype," The Journal of the American Association of Gynecologic Laparoscopists, vol. 11, no. 3, pp. 307-314, 2004.

[13] P. R. Koninckx, V. Gomel, A. Ussia, and L. Adamyan, "Role of the peritoneal cavity in the prevention of postoperative adhesions, pain, and fatigue," Fertility and Sterility, vol. 106, no. 5, pp. 998-1010, 2016.

[14] F. Nourbakhsh, M. I. Read, G. E. Barreto, and A. Sahebkar, "Boosting the autophagy-lysosomal pathway by phytochemicals: a potential therapeutic strategy against Alzheimer's disease," IUBMB life, vol. 72, no. 11, pp. 2360-2281, 2020.

[15] E. S. Elkhayat, S. R. Ibrahim, and M. A. Aziz, "Portulene, a new diterpene fromPortulaca oleraceaL," Journal of Asian Natural Products Research, vol. 10, no. 11, pp. 1039-1043, 2008.

[16] V. B. Rahimi, F. Ajam, H. Rakhshandeh, and V. R. Askari, “A pharmacological review on Portulaca oleracea L.: focusing on anti-inflammatory, anti- oxidant, immuno-modulatory and antitumor activities," Journal of Pharmacopuncture, vol. 22, no. 1, pp. 7-15, 2019.
[17] A. I. Mohamed and A. S. Hussein, "Chemical composition of purslane (Portulaca oleracea)," Plant Foods for Human Nutrition, vol. 45, no. 1, pp. 1-9, 1994.

[18] A. E. Abdel Moneim, "The neuroprotective effects of purslane (Portulaca oleracea) on rotenone-induced biochemical changes and apoptosis in brain of rat," CNS \& Neurological Disorders Drug Targets, vol. 12, no. 6, pp. 830-841, 2013.

[19] A. P. Simopoulos, D. X. Tan, L. C. Manchester, and R. J. Reiter, "Purslane: a plant source of omega-3 fatty acids and melatonin," Journal of Pineal Research, vol. 39, no. 3, pp. 331-332, 2005.

[20] H. L. Xin, Y. F. Xu, Y. H. Hou et al., “Two novel triterpenoids fromPortulaca oleraceaL," Helvetica Chimica Acta, vol. 91, no. 11, pp. 2075-2080, 2008.

[21] M. K. Uddin, A. S. Juraimi, M. S. Hossain, M. A. Nahar, M. E. Ali, and M. M. Rahman, "Purslane weed (Portulaca oleracea): a prospective plant source of nutrition, omega-3 fatty acid, and antioxidant attributes," Scientific World Journal, vol. 2014, article 951019, pp. 1-6, 2014.

[22] U. R. Palaniswamy, B. B. Bible, and R. J. Mcavoy, "Effect of nitrate: ammonium nitrogen ratio on oxalate levels of purslane," in Trends in New Crops and New Uses, J. Janick and A. Whipkey, Eds., ASHS Press, Alexandria, VA, 2002.

[23] M. I. El-Sayed, "Effects of _Portulaca oleracea_ L. seeds in treatment of type-2 diabetes mellitus patients as adjunctive and alternative therapy," Journal of Ethnopharmacology, vol. 137, no. 1, pp. 643-651, 2011.

[24] B. Chen, H. Zhou, W. Zhao, W. Zhou, Q. Yuan, and G. Yang, "Effects of aqueous extract of Portulaca oleracea L. on oxidative stress and liver, spleen leptin, PAR $\alpha$ and FAS mRNA expression in high-fat diet induced mice," Molecular Biology Reports, vol. 39, no. 8, pp. 7981-7988, 2012.

[25] J. Yan, L. R. Sun, Z. Y. Zhou et al., "Homoisoflavonoids from the medicinal plant Portulaca oleracea," Phytochemistry, vol. 80, pp. 37-41, 2012.

[26] G. Karimi, H. Hosseinzadeh, and N. Ettehad, "Evaluation of the gastric antiulcerogenic effects of Portulaca oleracea L. extracts in mice," Phytotherapy Research, vol. 18, no. 6, pp. 484-487, 2004.

[27] V. R. Askari, S. A. Rezaee, K. Abnous, M. Iranshahi, and M. H. Boskabady, "The influence of hydro-ethanolic extract of Portulaca oleracea $\mathrm{L}$. on $\mathrm{Th}_{1} / \mathrm{Th}_{2}$ balance in isolated human lymphocytes," Journal of Ethnopharmacology, vol. 194, pp. 1112-1121, 2016.

[28] V. Baradaran Rahimi, V. R. Askari, and S. H. Mousavi, "Ellagic acid dose and time-dependently abrogates d-galactoseinduced animal model of aging: investigating the role of PPAR- $\gamma$," Life Sciences, vol. 232, article 116595, 2019.

[29] V. Baradaran Rahimi, S. H. Mousavi, S. Haghighi, S. SoheiliFAR, and V. R. Askari, "Cytotoxicity and apoptogenic properties of the standardized extract of Portulaca oleracea on glioblastoma multiforme cancer cell line (U-87): a mechanistic study," EXCLI Journal, vol. 18, pp. 165-186, 2019.

[30] Y. Roohbakhsh, V. Baradaran Rahimi, S. Silakhori et al., "Evaluation of the effects of peritoneal lavage with Rosmarinus officinalis extract against the prevention of postsurgical-induced peritoneal adhesion," Planta Medica, vol. 86, no. 6, pp. 405$414,2020$.

[31] M. Ghadiri, V. Baradaran Rahimi, E. Moradi et al., "Standardised pomegranate peel extract lavage prevents postoperative peritoneal adhesion by regulating TGF- $\beta$ and VEGF levels," Inflammopharmacology, vol. 29, no. 3, pp. 855-868, 2021. 
[32] P. Liang, W. Shan, and Z. Zuo, "Perioperative use of cefazolin ameliorates postoperative cognitive dysfunction but induces gut inflammation in mice," Journal of Neuroinflammation, vol. 15, no. 1, p. 235, 2018.

[33] M. D. Sarap, K. S. Scher, and C. W. Jones, “Anaerobic coverage for wound prophylaxis: Comparison of cefazolin and cefoxitin," American Journal of Surgery, vol. 151, no. 2, pp. 213215, 1986.

[34] C. Dees, A. Akhmetshina, P. Zerr et al., "Platelet-derived serotonin links vascular disease and tissue fibrosis," The Journal of Experimental Medicine, vol. 208, no. 5, pp. 961-972, 2011.

[35] M. Hu, Y. Zhang, X. Guo et al., "Perturbed ovarian and uterine glucocorticoid receptor signaling accompanies the balanced regulation of mitochondrial function and $\mathrm{NF} \kappa \mathrm{B}$-mediated inflammation under conditions of hyperandrogenism and insulin resistance," Life Sciences, vol. 232, p. 116681, 2019.

[36] M. M. Bradford, "A rapid and sensitive method for the quantitation of microgram quantities of protein utilizing the principle of protein-dye binding," Analytical Biochemistry, vol. 72, no. 1-2, pp. 248-254, 1976.

[37] V. Baradaran Rahimi, H. Rakhshandeh, F. Raucci et al., "Antiinflammatory and anti-oxidant activity of Portulaca oleracea extract on LPS-induced rat lung injury," Molecules, vol. 24, no. 1, p. 139, 2019.

[38] R. Shirazinia, A. A. Golabchifar, V. B. Rahimi et al., "Protective effect of Opuntia dillenii haw fruit against lead acetate-induced hepatotoxicity: in vitro and in vivo studies," Evidence-based Complementary and Alternative Medicine, vol. 2021, Article ID 6698345, 13 pages, 2021.

[39] V. R. Askari, V. Baradaran Rahimi, S. A. Tabatabaee, and R. Shafiee-Nick, "Combination of imipramine, a sphingomyelinase inhibitor, and $\beta$-caryophyllene improve their therapeutic effects on experimental autoimmune encephalomyelitis (EAE)," International Immunopharmacology, vol. 77, article 105923, 2019.

[40] V. B. Rahimi, V. R. Askari, and S. H. Mousavi, "Ellagic acid reveals promising anti-aging effects against d-galactoseinduced aging on human neuroblastoma cell line, SH-SY5Y: a mechanistic study," Biomedicine \& Pharmacotherapy, vol. 108, pp. 1712-1724, 2018.

[41] R. M. Kamel, "Prevention of postoperative peritoneal adhesions," European Journal of Obstetrics, Gynecology, and Reproductive Biology, vol. 150, no. 2, pp. 111-118, 2010.

[42] C. Ren, L. Zhu, and J. C. Sun, "Creation of an animal model for post-operative adhesion prevention," Zhongguo Yi Xue Ke Xue Yuan Xue Bao. Acta Academiae Medicinae Sinicae, vol. 34, no. 2, pp. 109-115, 2012.

[43] Z. Alpay, G. M. Saed, and M. P. Diamond, "Postoperative adhesions: from formation to prevention," Seminars in Reproductive Medicine, vol. 26, no. 4, pp. 313-321, 2008.

[44] V. B. Rahimi, R. Shirazinia, N. Fereydouni et al., "Comparison of honey and dextrose solution on post-operative peritoneal adhesion in rat model," Biomedicine \& Pharmacotherapy, vol. 92, pp. 849-855, 2017.

[45] S. Samarghandian, A. Borji, and T. Farkhondeh, "Attenuation of oxidative stress and inflammation by Portulaca oleracea in streptozotocin-induced diabetic rats," Journal of EvidenceBased Complementary \& Alternative Medicine, vol. 22, no. 4, pp. 562-566, 2017.

[46] P. A. Lucas, D. J. Warejcka, H. E. Young, and B. Y. Lee, "Formation of Abdominal Adhesions Is Inhibited by Antibodies to
Transforming Growth Factor- $\beta 1$," The Journal of Surgical Research, vol. 65, no. 2, pp. 135-138, 1996.

[47] E. T. Condon, R. A. Cahill, D. B. O'Malley, N. J. Aherne, and H. P. Redmond, "Evaluation of postoperative peritoneal adhesion formation following perioperative nicotine administration," The Journal of Surgical Research, vol. 140, no. 1, pp. 135-138, 2007.

[48] A. P. Laddha and Y. A. Kulkarni, "VEGF and FGF-2: promising targets for the treatment of respiratory disorders," Respiratory Medicine, vol. 156, pp. 33-46, 2019.

[49] R. A. Cahill, J. H. Wang, S. Soohkai, and H. P. Redmond, "Mast cells facilitate local VEGF release as an early event in the pathogenesis of postoperative peritoneal adhesions," Surgery, vol. 140, no. 1, pp. 108-112, 2006.

[50] A. S. Lee, Y. J. Lee, S. M. Lee et al., “An aqueous extract of Portulaca oleraceaAmeliorates diabetic nephropathy through suppression of renal fibrosis and inflammation in diabetic $\mathrm{db} / \mathrm{db}$ mice," The American Journal of Chinese Medicine, vol. 40, no. 3, pp. 495-510, 2012.

[51] A. S. Lee, Y. J. Lee, S. M. Lee et al., "Portulaca oleracea ameliorates diabetic vascular inflammation and endothelial dysfunction in $\mathrm{db} / \mathrm{db}$ mice," Evidence-based Complementary and Alternative Medicine, vol. 2012, Article ID 741824, 9 pages, 2012.

[52] V. Belebecha, R. Casagrande, M. R. Urbano et al., "Effect of the platelet-rich plasma covering of polypropylene mesh on oxidative stress, inflammation, and adhesions," International Urogynecology Journal, vol. 31, no. 1, pp. 139-147, 2020.

[53] S. K. Nair, I. K. Bhat, and A. L. Aurora, "Role of proteolytic enzyme in the prevention of postoperative intraperitoneal adhesions," Archives of Surgery, vol. 108, no. 6, pp. 849-853, 1974.

[54] J. Chen, Y. P. Shi, and J. Y. Liu, "Determination of noradrenaline and dopamine in Chinese herbal extracts from Portulaca oleracea L. by high-performance liquid chromatography," Journal of Chromatography. A, vol. 1003, no. 1-2, pp. 127132, 2003.

[55] L. Xiang, D. Xing, W. Wang, R. Wang, Y. Ding, and L. Du, "Alkaloids from Portulaca oleracea L.," Phytochemistry, vol. 66, no. 21, pp. 2595-2601, 2005.

[56] J. L. Tian, X. Liang, P. Y. Gao et al., "Two new alkaloids from Portulaca oleracea and their cytotoxic activities," Journal of Asian Natural Products Research, vol. 16, no. 3, pp. 259-264, 2014.

[57] X. Liang, J. Tian, L. Li et al., "Rapid determination of eight bioactive alkaloids in Portulaca oleracea L. by the optimal microwave extraction combined with positive -negative conversion multiple reaction monitor (+/-MRM) technology," Talanta, vol. 120, pp. 167-172, 2014.

[58] N. Sakai, K. Inada, M. Okamoto, Y. Shizuri, and Y. Fukuyama, "Portuloside A, a monoterpene glucoside, from _Portulaca oleracea_, Phytochemistry, vol. 42, no. 6, pp. 1625-1628, 1996.

[59] Y. Seo, J. Shin, H. J. Cha et al., "A new monoterpene glucoside from Portulaca oleracea," Bulletin-Korean Chemical Society, vol. 24, pp. 1475-1477, 2003.

[60] H.-L. Xin, Y.-F. Xu, Y.-H. Hou et al., "Two novel triterpenoids from Portulaca oleracea L," Helvetica Chimica Acta, vol. 91, no. 11, pp. 2075-2080, 2008.

[61] X. Xu, L. Yu, and G. Chen, "Determination of flavonoids in _Portulaca oleracea_ L. by capillary electrophoresis with 
electrochemical detection," Journal of Pharmaceutical and Biomedical Analysis, vol. 41, no. 2, pp. 493-499, 2006.

[62] H. Zhu, Y. Wang, Y. Liu, Y. Xia, and T. Tang, "Analysis of flavonoids in Portulaca oleracea L. by UV-Vis spectrophotometry with comparative study on different extraction technologies," Food Analytical Methods, vol. 3, no. 2, pp. 9097, 2010.

[63] U. R. Palaniswamy, R. J. Mcavoy, and B. B. Bible, "Stage of harvest and polyunsaturated essential fatty acid concentrations in purslane (Portulaca oleraceae) leaves," Journal of Agricultural and Food Chemistry, vol. 49, no. 7, pp. 3490-3493, 2001.

[64] Z. Yang, C. Liu, L. Xiang, and Y. Zheng, "Phenolic alkaloids as a new class of antioxidants in Portulaca oleracea," Phytotherapy Research, vol. 23, no. 7, pp. 1032-1035, 2009.

[65] Z. Cheng, D. Wang, W. Zhang et al., "LC determination and pharmacokinetic study of the main phenolic components of Portulaca oleracea L. extract in rat plasma after oral administration," Natural Product Research, vol. 26, no. 23, pp. 22472250, 2012. 